\title{
The Impact of Uncertainty on National Port Throughput: Evidence From European Countries
}

\author{
๑ B Bayram Bilge Sağlam, (® Resul Tepe, ๑ Abdullah Açık
}

Dokuz Eylül University Maritime Faculty, Department of Maritime Business Administration, İzmir, Turkey

\begin{abstract}
This study investigates the effect of economic policy uncertainties on national port throughputs of selected European countries. For this purpose, we used quarterly observations of 21 European countries covering the periods between 2005 Q1 and 2018 Q3. The Granger noncausality test was used for heterogeneous panel data models and we found that economic policy uncertainties have a considerable impact on port throughputs in the selected sample. Causality tests on individual country level have shown that uncertainties in Belgium, Denmark, Finland, Ireland, Poland, Slovenia, Spain, and the United Kingdom have an influence over their port throughputs. Moreover, the present results show cross-sectional dependencies in uncertainty and port throughput variables, indicating that collaborative efforts by European nations are needed to avoid the risks associated with economic policy uncertainties due to the integrated structure of the countries.
\end{abstract}

Keywords

Economic policy uncertainty, Port throughput, Panel causality

\section{Introduction}

It is well known that economic policy uncertainties pose a challenge for the decision makers in the port industry because competition in this industry heavily depends on capital intensive investments [1]. Decision makers must seek ways to enhance competitiveness through investment projects that aim to expand capacity and productivity. However, carrying out these costly, extensive, and irreversible investment projects becomes difficult, especially when the market is under the influence of uncertainty [2]. To eliminate the risk of taking decisions that would lead to negative outcomes like congestions, idle capacities, and unproductivity, decision makers must understand the relationship between economic policy uncertainty and the performance of their businesses [3]. This relationship characteristic may vary in different countries of the world depending on the status of macroeconomic fundamentals [4]. Therefore, it is also important for decision makers to understand the uncertainty level of the market and that of the country in which they operate.
Uncertainty has become one of the prominent research topics in port economics due to its significant impact on management decisions. In this context, Lagoudis et al. [5] proposed a three-phase model to evaluate port investment strategies in uncertain environments. The model starts with an assessment of future uncertainties and is followed by an identification of investment strategies and their comparison. Linking the level of uncertainty with port capacity planning decisions, Balliauw et al. [6] identified real options models as a suitable method for investment project valuations and revealed how this method helps decision makers to determine the right size for their projects. Zheng and Negenborn [7] also used a real option approach to investigate timing decisions in terminal constructions by considering demand uncertainty. However, the related literature is not limited to the studies focused on the impact of uncertainty on investment decisions since the level of uncertainty affects many other managerial decisions in the port industry. For instance, Tovar and Wall [8] focused on demand uncertainty from a cost perspective and quantified the impact of demand changeability on port costs of Spanish

To cite this article: B.B. Sağlam, R. Tepe, A. Açık, “The Impact of Uncertainty on National Port Throughput: Evidence From European Countries.” Journal of ETA Maritime Science, vol. 9(2), pp. 66-73, 2021.

(C) Copyright 2021 by the Journal of ETA Maritime Science published by UCTEA Chamber of Marine Engineers 
port authorities. The study of Satta et al. [9] focused on the relation between uncertain market conditions and the formation of interorganizational networks.

Despite the growing scientific interest in uncertainty in the port economics literature, answer to the basic question of "Does economic policy uncertainty have an impact on the port throughput (PT) of nations?" still remains vague. We believe that this question needs to be addressed with multi-country analysis, considering that economic policy uncertainty in every individual country may vary and spread to one another. Hence, the aim is to reveal both country-specific and general results, which will help decision makers in gaining a clearer understanding of the extent to which their ports' performances are influenced by the economic policy uncertainties of the countries in which they operate. From the port investment perspective, present findings would be helpful for the global terminal investors since the level of economic policy uncertainty in the targeted country is one of the most important macroeconomic indicators that need to be taken into account to ensure a predictable return of investment.

To reveal the link between economic policy uncertainty and PT, we use the data from world uncertainty index (WUI) for evaluating the economic policy uncertainty of selected European countries. WUI is developed by Ahir et al. [10], and it has become one of the highly preferred tools to manifest the uncertainty levels of countries in related literature. Gozgor et al. [11], linked economic uncertainty and domestic credits whereas Karabulut et al. [12] focused on the relationship between commodity prices and world trade uncertainty. These are the two examples that use data from WUI to assess the level of economic policy uncertainty. Until now, studies on uncertainty in the port economics literature have measured uncertainty with different scales. Using the WUI, which measures uncertainty with a standard structure for each country, allows these findings to compare with similar studies that can be conducted in the future. Besides the data from WUI, the present study evaluates the port performance of the selected countries using the cargo throughput data collected from Eurostat [13]. However, developments in one country are likely to affect other countries considering the integrated economic and political structure of European countries. In this context, we considered the causality analysis developed by Dumitrescu and Hurlin [14]. Unlike standard panel data analyzes, this method takes cross-sectional dependency (CD) and heterogeneity into account.

The rest of the paper is structured as follows: Section 2 explains the methodology of the study and presents the data analysis, which is followed by the results of the analysis (Section 3). Finally, the study concludes with a discussion of the findings of policy implications that need to be considered both by the port managers and national policymakers of international trade., limitations, and scope for future research (Section 4).

\section{Data and Methodology}

The causality analysis proposed by Dumitrescu and Hurlin [14] was considered for this work and the effects of uncertainty on port traffic in European countries were studied. This method fits well with the proposed study as it considers both CDs and heterogeneity. Information on the data that is used in the present model is given in the following section.

\subsection{Data}

The present dataset consists of 55 quarterly observations of 21 European countries and covers the period between 2005 Q1 and 2018 Q3. The selected countries are listed in alphabetical order as follows: Belgium, Bulgaria, Croatia, Denmark, Finland, France, Germany, Greece, Ireland, Italy, Latvia, Lithuania, Netherlands, Norway, Poland, Portugal, Romania, Slovenia, Spain, Sweden, and United Kingdom. Cyprus, Estonia, and Malta are excluded from the sample since they are not included in the WUI list.

The PT variable shows the gross weight of goods handled in that country based on thousand tones. PT data of the European countries are obtained from Eurostat database [13]. Table 1 shows descriptive statistics on the PT. These statistics provide vital information to understand the position of each country in terms of PT in the sample. Skewness and kurtosis values provide information about the distribution of the variables. Symmetry of distribution can be interpreted by skewness and tail features by kurtosis. When the mean values of the cargo traffic of the ports are examined, the highest port traffic is observed in the Netherlands (135 million tons), and the lowest traffic is observed in Slovenia (4.3 million tons). This data reveals that the Netherlands is one of the main port centers for the European countries. Thus, the port outputs in the countries within the sample differ significantly.

The WUI has been developed by Ahir et al. [10]. They have formed quarterly indices for 143 countries starting in 1996 Q1 and used country reports of the Economist Intelligence Unit to develop the index. These reports include major political and economic developments and forecasts of economic policy conditions in each country. The WUI in the present study refers to the uncertainty score for the related country, and data for the variable is obtained from EPU [15]. Table 2 presents descriptive statistics of the data. These statistics are important for identifying different characteristics of the countries in the 
Table 1. Descriptive statistics of port throughputs

\begin{tabular}{|c|c|c|c|c|c|c|c|c|}
\hline Country & Mean & Median & Maximum & Minimum & Standard deviation & Skew. & Kurt. & Obs. \\
\hline Bulgaria & 6604.418 & 6544.000 & 9097.000 & 4184.000 & 1044.134 & 0.311602 & 3.075233 & 55 \\
\hline Croatia & 4687.618 & 4667.000 & 6656.000 & 2883.000 & 923.2808 & 0.250518 & 2.529736 & 55 \\
\hline Denmark & 21339.73 & 21161.00 & 25712.00 & 18347.00 & 1872.042 & 0.673074 & 2.696900 & 55 \\
\hline Germany & 73259.69 & 74256.00 & 82140.00 & 63002.00 & 4099.365 & -0.656427 & 3.135955 & 55 \\
\hline Greece & 33715.60 & 33229.00 & 44300.00 & 24897.00 & 5012.965 & 0.222002 & 2.247071 & 55 \\
\hline Ireland & 11783.85 & 11739.00 & 13344.00 & 9070.000 & 827.7771 & -0.516026 & 3.630215 & 55 \\
\hline Netherlands & 135614.1 & 137665.0 & 154711.0 & 112910.0 & 11763.06 & -0.414230 & 2.074033 & 55 \\
\hline Norway & 44753.04 & 45119.00 & 49820.00 & 37820.00 & 2524.495 & -0.648840 & 3.326053 & 55 \\
\hline Poland & 15375.49 & 15041.00 & 23328.00 & 10060.00 & 3015.649 & 0.584731 & 2.964100 & 55 \\
\hline Portugal & 18199.91 & 17091.00 & 23816.00 & 13668.00 & 2882.460 & 0.590992 & 1.975018 & 55 \\
\hline Romania & 10815.73 & 10754.00 & 14444.00 & 7826.000 & 1686.887 & 0.111477 & 2.095042 & 55 \\
\hline Slovenia & 4305.909 & 4177.000 & 5979.000 & 2720.000 & 796.0325 & 0.242468 & 2.481617 & 55 \\
\hline Spain & 105481.5 & 104682.0 & 128699.0 & 85952.00 & 9617.509 & 0.389028 & 2.932628 & 55 \\
\hline Sweden & 41321.00 & 41943.00 & 46353.00 & 35428.00 & 2245.290 & -0.462833 & 3.370118 & 55 \\
\hline
\end{tabular}

sample. The mean values show that the United Kingdom has the highest uncertainty (0.374) whereas Finland has the lowest uncertainty (0.118). The highest PT is about 30 times that of the lowest throughput whereas the highest uncertainty is about three times that of the lowest uncertainty. This situation can be interpreted as the uncertainty being experienced in a more commonly in the European countries.

\subsection{Testing Cross Sectional Dependence and Homogeneity}

Recent developments in panel data causality analysis highlighted two major econometric problems: Crosssectional dependence and heterogeneity across the sample [16]. Due to international commercial relationships, and financial and economic integration, change in any country can easily be transferred to other countries [17]. Therefore, estimation results in cross sectionally dependent panel data are often inconsistent and upward biased [18]. Consequently, testing the crosssectional condition is of great importance for panel causality analysis.

In this study, the lagrange multiplier (LM) test developed by Breusch and Pagan [19], CD and CD LM test developed by Pesaran [20], and LM adjusted test developed by Pesaran et al. [21] are used to check for CD. To compute the LM test, the following empirical model should be estimated (formula 1 is below):

$$
y_{i t}=a_{i}+\beta_{i} x_{i t}+\mu_{i} \text { for } i=1,2,3, \ldots, N ; t=1,2, \ldots, T
$$

Where $i$ indicates cross-section dimension; $t$ indicates time dimension; $y_{i t}$ is the dependent variable; $x_{i t}$ is a vector of independent ones; $a_{i}$ and $\beta_{i}$ indicate the individual intercepts and slope coefficients across the sample. The null hypothesis related to the absence of cross-sectional dependance is expressed as follows:

$H_{0}: \operatorname{Cov}\left(\mu_{i t} \mu_{j t}\right)=0$ for all $\mathrm{t}$ and $\mathrm{i} \neq \mathrm{j}$ 
Table 2. Descriptive statistics of uncertainty

\begin{tabular}{|c|c|c|c|c|c|c|c|c|}
\hline Country & Mean & Median & Maximum & Minimum & Standard deviation & Skew. & Kurt. & Obs. \\
\hline Bulgaria & 0.216541 & 0.167898 & 0.686048 & 0.000000 & 0.188498 & 0.938704 & 2.980879 & 55 \\
\hline Croatia & 0.151772 & 0.115794 & 0.604804 & 0.000000 & 0.131944 & 1.207963 & 4.623405 & 55 \\
\hline Denmark & 0.209118 & 0.142572 & 1.074460 & 0.000000 & 0.187795 & 2.006200 & 9.404350 & 55 \\
\hline Germany & 0.197630 & 0.180554 & 0.928103 & 0.000000 & 0.172505 & 1.662998 & 7.614112 & 55 \\
\hline Greece & 0.157499 & 0.094060 & 0.689070 & 0.000000 & 0.185962 & 1.146794 & 3.362287 & 55 \\
\hline Ireland & 0.212636 & 0.210585 & 0.871903 & 0.000000 & 0.186782 & 1.015775 & 4.342964 & 55 \\
\hline Italy & 0.225558 & 0.201518 & 0.667646 & 0.000000 & 0.180546 & 0.429957 & 2.205035 & 55 \\
\hline Netherlands & 0.196546 & 0.157381 & 0.756920 & 0.000000 & 0.188609 & 1.096425 & 3.779137 & 55 \\
\hline Norway & 0.229331 & 0.205065 & 1.382685 & 0.000000 & 0.220483 & 2.847575 & 14.90800 & 55 \\
\hline Poland & 0.234885 & 0.226638 & 0.917684 & 0.000000 & 0.184760 & 1.506098 & 6.001958 & 55 \\
\hline Portugal & 0.184129 & 0.177788 & 0.591331 & 0.000000 & 0.140650 & 0.683845 & 3.146598 & 55 \\
\hline Romania & 0.170079 & 0.120518 & 0.604047 & 0.000000 & 0.134684 & 1.089185 & 4.131570 & 55 \\
\hline Slovenia & 0.170683 & 0.123548 & 0.698432 & 0.000000 & 0.171560 & 1.101345 & 4.007376 & 55 \\
\hline Spain & 0.223278 & 0.194137 & 0.819001 & 0.000000 & 0.169433 & 0.875883 & 4.244637 & 55 \\
\hline Sweden & 0.202967 & 0.158328 & 0.740101 & 0.000000 & 0.163471 & 0.887030 & 3.413207 & 55 \\
\hline \multicolumn{9}{|c|}{$\begin{array}{l}\text { Skew: Skewness value, Kurt: Kurtosis value } \\
\text { Source: Economic Policy Uncertainty [15] }\end{array}$} \\
\hline
\end{tabular}

The alternative hypothesis that indicates cross-sectional dependence is expressed as follows:

$H_{a}: \operatorname{Cov}\left(\mu_{i t} \mu_{j t}\right) \neq 0$ for at least one pair of $\mathrm{i} \neq \mathrm{j}$

The LM test for testing the null of cross-sectional dependence is introduced by Breusch and Pagan [19] as follows (formula 2 is below):

$$
L M=T \sum_{i=1}^{N-1} \sum_{j=i+1}^{N} \hat{\rho}_{i j}^{2} \sim \chi_{N(N-1) / 2}^{2}
$$

where $\hat{\rho}_{i j}$ indicates a pair-wise correlation of the residuals from equation (1) for each $i$. The LM test is effective when $\mathrm{N}$ is very small compared to T. Due to this limitation, Pesaran [20] suggested the structured type of LM test for large panels as (formula 3 is below):

$$
C D_{l m}=\left(\frac{1}{N(N-1)}\right)^{1 / 2} \sum_{i=1}^{N-1} \sum_{j=i+1}^{N}\left(T \hat{\rho}_{i j}^{2}-1\right) \sim N(0,1)
$$

However, when $\mathrm{N}$ is large and $\mathrm{T}$ is small, the $C D_{l m}$ test is subject to size distortions. Hence, Pesaran [20] suggested a more valid CD test as (formula 4 is below):

$$
C D=\sqrt{\left(\frac{2 T}{N(N-1)}\right)}\left(\sum_{i=1}^{N-1} \sum_{j=i+1}^{N} \hat{\rho}_{i j}\right) \sim N(0,1)
$$

Pesaran et al. [21] indicated in further studies that power of the cross-sectional dependence test diminishes when the mean pair-wise correlation of the population is close to 0 . Therefore, the authors suggested a bias-adjusted test by modifying the LM test. The improved test is as follows (formula 5 is below):

$$
L M_{a d j}=\sqrt{\left(\frac{2}{N(N-1)}\right)} \sum_{i=1}^{N-1} \sum_{j=i+1}^{N} \frac{(T-k) \hat{\rho}_{i j}^{2}-\mu_{T i j}}{\sqrt{v_{T i j}^{2}}} \sim N(0,1)
$$

The panel causality analysis used in the study can be applied both when cross-sectional dependencies exist 
or not. The cross-sectional dependence is also of great importance in selecting the unit root test preferred in the analysis. If there is no $\mathrm{CD}$, the unit root tests described as first-generation are used; otherwise, second-generation unit roots are preferred.

If intense cross-sectional dependence is a concern, every country in the sample may have similar economic activity structures. Hence, assuming slope homogeneity may lead to illusive estimates when the structure of the panel becomes heterogeneous [22]. Pesaran and Yamagata [23] developed one of the most widely used tests for the null hypothesis of homogeneity, called as Delta test. At first, an improved type of Swamy test is calculated as follows (formula 6 is below):

$$
\tilde{S}=\sum_{i=1}^{N}\left(\tilde{\beta}_{i}-\tilde{\beta}_{W F E}\right)^{\prime} \frac{x_{i}^{\prime} M_{T} x_{i}}{\tilde{\sigma}_{i}^{2}}\left(\tilde{\beta}_{i}-\tilde{\beta}_{W F E}\right)
$$

Where $\tilde{\beta}_{i}$ indicates pooled OLS; $\tilde{\beta}_{W F E}$ indicates the weighted fixed effect estimation of the first equation; $M_{T}$ indicates identity matrix of order $\mathrm{T}$; $\tilde{\sigma}_{i}^{2}$ indicates the estimator of $\sigma_{i}^{2}$. For the test statistics, the following equation is computed (formula 7 is below):

$$
\tilde{\Delta}=\sqrt{N}\left(\frac{N^{-1} \tilde{S}-k}{\sqrt{2 k(T-k-1) / T+1}}\right) \sim N(0,1)
$$

All the mentioned cross-sectional dependence tests and homogeneity tests are applied to the data set, and the following steps are structured based on CD results.

\subsection{Testing Unit Root}

The method proposed by Dumitrescu and Hurlin [14] requires stationary data. Considering the outcomes of the cross-sectional dependence and homogeneity tests, Smith et al. [24] proposed the Bootstrap-IPS (Im, Pesaran, Shin) test to determine integration properties of PT and the WUI. The unit root test is an improved type of test developed by Im et al. [25] and considers the cross-sectional dependence into account using bootstrap blocks.

In the unit root test suggested by IPS [25], the augmented Dickey-Fuller (ADF) test is implemented to the individual series, which is computed as follows (formula 8 is below):

$$
\Delta y_{i, t}=\propto_{i}+\beta_{i} y_{i, t-1}+\sum_{j=1}^{p i} \rho_{i, j} \Delta y_{i, t-j}+\gamma_{i t}+\varepsilon_{i, t}
$$

Then statistics for IPS is calculated by considering the mean of the individual statistics of ADF as follows (formula 9 is below):

$$
t_{N T}=\frac{1}{N} \sum_{t=1}^{N} t_{i T}\left(p_{i}\right)
$$

IPS proposes the uses of the standardized statistic as shown, by assuming that cross-sections are independent (formula 10 is below):

$t_{b}=\frac{\sqrt{N}\left(t_{N T}\right)-E\left(t_{T}\right)}{\sqrt{\operatorname{Var}}\left(t_{T}\right)}$

The Bootstrap-IPS test developed by Smith et al. [24] is the bootstrap version of the IPS [25] and considers crosssectional dependence across countries. The null hypotheses of these tests point to the unit root, and if the unit root is detected, differences in the series are included in the panel Granger causality method.

\subsection{Panel Granger Causality Test}

In this research, we preferred to apply panel causality analysis facilitating the modeling of cross-sections, which yield effective results even for short time periods as the number of observations is high [26]. The method developed by Dumitrescu and Hurlin [14] is used in this study based on the panel causality tests. In this method, assumption related to the difference of all coefficients across crosssections makes the method more reliable and robust than traditional Granger tests [27]. Thus, heterogeneity in the data set is considered. Besides, the $\mathrm{T}>\mathrm{N}$ constraint, which is a requirement of some other panel causality tests such as Emirmahmutoglu and Kose [28], has also disappeared in the Dumitrescu and Hurlin [14] approach [29]. Finally, in Europe, which has an integrated economic structure, the shocks seen in one country will spread to other ones. In this respect, the method we have chosen can be applied against this situation since it also takes the possible CD into account. This method must be used with stationary variables having fixed coefficients in vector autoregressive structure [27].

Dumitrescu and Hurlin [14] predicated the stationary fixedeffects panel equation for non-homogeneous panels as follows (formula 11 is below):

$$
\Delta P_{i, t}=a_{i}+\sum_{k=1}^{K} y_{i}^{k} \Delta P_{i, t-k}+\sum_{k=1}^{K} \beta_{i}^{k} U I_{i, t-k}+\varepsilon_{i, t}
$$

Where $\Delta$ is the difference operator; $\mathrm{P}$ is the $\log$ of PT; UI is the $\log$ of uncertainty index for country $\mathrm{i}(\mathrm{i}=1,2, \ldots \mathrm{N})$ in period; $t, \gamma$, and $\beta$ are parameters that change across 
countries; $\varepsilon$ are residuals. As a result of this analysis, both individual causality results and panel causality results are obtained in two directions: from uncertainty to port and port to uncertainty.

\section{Results}

The LM test developed by Breusch and Pagan [19], CD and CD LM test developed by Pesaran [20], and LM adjusted test developed by Pesaran et al. [21] were all applied to test the cross-sectional dependence in the data and model. Table 3 presents the results. The null hypothesis of these tests indicates no cross-sectional dependence. LM, CD, and LM adjusted tests are generally used for $\mathrm{T}>\mathrm{N}$ cases whereas the first two reject the null hypothesis for the WUI variable. Delta test indicated that the null hypothesis of homogeneity could not be rejected for the variable. For the PT variable, the null hypotheses were rejected in both cross-sectional dependence and homogeneity tests. In the test results applied for the model, both null hypotheses are rejected. Based on these results, it was determined that unit root tests defined as the second generation were necessary to check the stationary and causality method suggested by Dumitrescu and Hurlin [14].

For the causality method developed by Dumitrescu and Hurlin [14], the series must be stationary. Thus, considering the dependence of the cross-sections in the series, the Bootstrap-IPS unit root test was implemented on the variables, and subsequent results are shown in Table 4. To calculate the critical values, the initial values are 50 for

Table 3. Results of the pre-tests before causality analysis

\begin{tabular}{|c|c|c|c|}
\hline Test & WUI & PT & Model \\
\hline LM & $247.484[0.039]$ & $443.62[0.000]$ & $2393.466[0.000]$ \\
\hline CD LM & $1.829[0.034]$ & $11.400[0.000]$ & $106.542[0.000]$ \\
\hline CD & $-4.798[0.000]$ & $-1.176[0.000]$ & $25.602[0.000]$ \\
\hline LM Adj. & $0.265[0.395]$ & $33.345[0.000]$ & $6.159[0.000]$ \\
\hline Delta & $0.667[0.252]$ & $5.054[0.000]$ & $2.195[0.014]$ \\
\hline Delta Adj. & $0.686[0.246]$ & $5.198[0.000]$ & $2.256[0.012]$ \\
\hline \multicolumn{4}{|c|}{ Probability values are shown within parenthesis } \\
LM: Lagrange multiplier, CD: Cross-sectional dependency, WUI: World \\
uncertainty index, PT: Port throughput \\
\hline
\end{tabular}

block size, 6 for maximum lags, and 1000 for the number of bootstrap replications. Based on the results, the WUI variable is stationary, and the null of unit root hypothesis for the PT cannot be rejected. Thus, the analysis was continued using the first difference of the PT.

GAUSS statistical software was used to apply the panel causality analysis proposed by Dumitrescu and Hurlin [14]. Since the data set consists of quarterly observations, the number of lags is selected as 6 . To find the most appropriate lag, the Akaike information criterion was selected. According to the results, significant causalities from WUI to PT were obtained based on individual countries and panels. Individual results indicated that uncertainties in Belgium, Denmark, Finland, Ireland, Poland, Slovenia, Spain, and the United Kingdom affect their PTs. However, cargo traffic in ports does not affect uncertainty in the countries [5].

\section{Conclusion and Policy Implications}

This study has focused on the relationship between economic policy uncertainty and PT in the context of European countries. Unlike the current literature on port economics, we used the data gathered from WUI to reflect country-specific uncertainty levels. Therefore, problems related to the unstandardized measurement of uncertainty in countries are minimized since macroeconomic indicators in each country may have different characteristics.

The analysis provided empirical results revealing the significant impact of uncertainty on throughputs of European ports. Moreover, the present results indicate that both the cargo traffic of ports and uncertainties of the countries have cross-sectional dependence showing that the changes experienced by any of the European countries affect other countries as well. This finding can be explained by the integrated nature of European economics and policy. Hence, these results highlight the need for collaborative efforts by European nations to avoid the risks associated with economic policy uncertainties.

We believe that the present results will be useful to the European policy makers as well as port investors. Since port investments are costly investments that require decision making in the long term, uncertainty in the investment environment should be low and financial

Table 4. Bootstrap-IPS test results

\begin{tabular}{|c|c|c|c|c|c|c|c|c|}
\hline & \multicolumn{4}{|c|}{ Level } & \multicolumn{4}{|c|}{ First difference } \\
\hline & C & C\&T & C & C\&T & C & C\&T & C & C\&T \\
\hline \multicolumn{9}{|c|}{ Probability values are shown within parenthesis. } \\
\hline
\end{tabular}


Table 5. Bivariate causality test results

\begin{tabular}{|c|c|c|c|c|c|c|}
\hline \multirow[b]{2}{*}{ Country } & \multicolumn{3}{|c|}{ (1) From WUI to PT } & \multicolumn{3}{|c|}{ (2) From PT to WUI } \\
\hline & Lag & Wald & Prob. & Lag & Wald & Prob. \\
\hline Belgium & 1.000 & 23.942 & 0.000 & 1.000 & 0.298 & 0.585 \\
\hline Bulgaria & 3.000 & 0.501 & 0.919 & 3.000 & 0.602 & 0.896 \\
\hline Croatia & 3.000 & 0.771 & 0.856 & 3.000 & 4.571 & 0.206 \\
\hline Denmark & 3.000 & 10.124 & 0.018 & 3.000 & 2.133 & 0.545 \\
\hline Finland & 4.000 & 10.693 & 0.030 & 4.000 & 3.077 & 0.545 \\
\hline France & 2.000 & 1.982 & 0.371 & 2.000 & 3.110 & 0.211 \\
\hline Germany & 3.000 & 5.746 & 0.125 & 3.000 & 2.940 & 0.401 \\
\hline Greece & 4.000 & 4.719 & 0.317 & 4.000 & 5.425 & 0.246 \\
\hline Ireland & 4.000 & 10.645 & 0.031 & 4.000 & 0.883 & 0.927 \\
\hline Italy & 4.000 & 5.901 & 0.207 & 4.000 & 4.013 & 0.404 \\
\hline Latvia & 2.000 & 3.327 & 0.190 & 2.000 & 4.098 & 0.129 \\
\hline Lithuania & 6.000 & 5.282 & 0.508 & 6.000 & 8.721 & 0.190 \\
\hline Netherlands & 4.000 & 2.958 & 0.565 & 4.000 & 7.376 & 0.117 \\
\hline Norway & 4.000 & 6.133 & 0.189 & 4.000 & 1.576 & 0.813 \\
\hline Poland & 6.000 & 19.032 & 0.004 & 6.000 & 6.379 & 0.382 \\
\hline Portugal & 3.000 & 3.863 & 0.277 & 3.000 & 0.606 & 0.895 \\
\hline Romania & 3.000 & 2.525 & 0.471 & 3.000 & 0.271 & 0.965 \\
\hline Slovenia & 6.000 & 11.459 & 0.075 & 6.000 & 8.823 & 0.184 \\
\hline Spain & 2.000 & 6.118 & 0.047 & 2.000 & 0.776 & 0.678 \\
\hline Sweden & 6.000 & 9.348 & 0.155 & 6.000 & 9.349 & 0.155 \\
\hline United Kingdom & 2.000 & 13.643 & 0.001 & 2.000 & 1.456 & 0.483 \\
\hline Panel Z_NT & & 6.835 & 0.000 & & 1.121 & 0.904 \\
\hline \multicolumn{7}{|c|}{ Bootstrapped CVs for (1): 2.097 (10\%), 2.634 (5\%), 3.949 (1\%); Bootstrapped CVs for (2): 1.852 (10\%), 2.461 (5\%), 3.559 (1\%) } \\
\hline
\end{tabular}

returns should be predictable in the long term. Our results also explain how port managers in each country should consider uncertainty as a factor influencing investment decisions since the relationship between uncertainty and PT varies in different countries. Thus, ports operating in countries where the impact of uncertainty is significant may have to work harder to implement flexible and agile solutions.

Due to the increasing interdependence in world economies, the economic policy uncertainty has become a determining factor in port business due to its ties with international trade. Especially, heightened economic tensions between China and the United States and growth in protectionism are the two most important events that increase uncertainty and risks in the maritime trade environment. The decision of the United Kingdom and Northern Ireland to leave the European Union (Brexit) has had a relatively small impact on global maritime trade so far; however, it remains a threat for the future. The effects of the global pandemic that emerged in 2019 and spread to the world in 2020, will also be seen more clearly in the near future. In such an environment, where decisions made by any economic or political actor can quickly affect others, there is only one consequence, and that is uncertainty. In a competitive environment where uncertainty is so decisive, it is necessary to perceive changes quickly, make the counter move, and do this with as flexible decision processes as possible. In this respect, future research should focus on the ongoing influence of economic policy uncertainty, resulting in the aforementioned current events on international trade in general and port management in particular.

Our study has certain limitations that can be addressed in future research. The true nature of the relationship between uncertainty and port performance needs to be evaluated by increasing the sample size. Another limitation is the availability of the PT data. While the WUI published data from 1996 to date, PT data obtained from Eurostat does not provide data before 2005. This mismatch in the dataset compelled us to carry out our research on a relatively limited time period. 


\section{Authorship Contributions}

Concept design: B.B. Sağlam, R. Tepe, A. Açık, Data Collection or Processing: B.B. Sağlam, R. Tepe, A. Açık, Analysis or Interpretation: B.B. Sağlam, R. Tepe, A. Açık, Literature Review: B.B. Sağlam, R. Tepe, Writing, Reviewing and Editing: B.B. Sağlam, R. Tepe.

Funding: The authors declared that this study received no financial support.

\section{References}

[1] H.M. Meersman, "Port investments in an uncertain environment." Research in Transportation Economics, vol. 13, pp. 279-298, 2005.

[2] H. Bendall, and A.F. Stent, "Investment strategies in market uncertainty." Maritime Policy \& Management, vol. 30, pp. 293303, 2003.

[3] H.C. Chen and S.M. Liu, "Should ports expand their facilities under congestion and uncertainty?." Transportation Research Part B: Methodological, vol. 85, pp. 109-131, March 2016.

[4] D. Bonciani and M. Ricci, "The global effects of global risk and uncertainty," Working Paper Series 2179, European Central Bank.

[5] I.N. Lagoudis, J.B. Rice Jr, and J.B. Salminen, "Port investment strategies under uncertainty: The case of a Southeast Asian multipurpose port," The Asian Journal of Shipping and Logistics, vol. 30, 299-319, Dec 2014.

[6] M. Balliauw, H. Meersman, E. Van de Voorde, T. Vanelslander, "Towards improved port capacity investment decisions under uncertainty: a real options approach," Transport Reviews, vol. 39 pp. 531-552, Nov 2018.

[7] S. Zheng, and R.R. Negenborn, "Terminal investment timing decisions in a competitive setting with uncertainty using a real option approach," Maritime Policy \& Management, vol. 44, pp. 392-411, Dec 2018.

[8] B. Tovar and A. Wall, "The impact of demand uncertainty on port infrastructure costs: Useful information for regulators," Transport Policy, vol. 33, pp. 176-183, May 2014.

[9] G. Satta, F. Parola, and S. Caschili, "Dealing with uncertainty and volatility in the port industry network: social and instrumental antecedents of "clique" survival," Maritime Policy \& Management, vol. 41, pp.615-633, Nov 2014.

[10] H. Ahir, N. Bloom and D. Furceri, "The World Uncertainty Index," Economic Policy Uncertainty, pp.1-33, 2018. [Online]. Available: https://www.policyuncertainty.com/media/WUI mimeo_10_29.pdf. [Accessed: March 30, 2019].

[11] G. Gozgor, E. Demir, J. Belas and S. Yesilyurt, "Does economic uncertainty affect domestic credits? an empirical investigation," Journal of International Financial Markets, Institutions and Money, vol. 63, pp. 1-11, Nov 2019.

[12] G. Karabulut, M.H. Bilgin and A.C. Doker, "The relationship between commodity prices and world trade uncertainty. Economic Analysis and Policy, vol. 66, pp. 276-281, Jun 2020.

[13] Eurostat, "Port Cargo Throughput Statistics," Eurostat, 2019. Available: https://ec.europa.eu/eurostat/databrowser/view/ mar_qg_qm_cwh/default/table?lang=en. [Accessed: Oct. 23, 2019].
[14] E.I. Dumitrescu and C. Hurlin, "Testing for granger non-causality in heterogeneous panels." Economic Modelling, vol. 29 pp. 14501460, Jul 2012.

[15] Economic Policy Uncertainty, "Economic Policy Uncertainty Index," Economic Policy Uncertainty, 2019. Available: policyuncertainty.com. [Accessed: Oct. 23, 2019].

[16] Y. Wolde-Rufael, "Electricity consumption and economic growth in transition countries: a revisit using bootstrap panel Granger causality analysis," Energy Economics, vol. 44, pp. 325-330, Jul 2014.

[17] S. Nazlioglu, F. Lebe, and S. Kayhan, "Nuclear energy consumption and economic growth in OECD countries, cross-sectionally dependent heterogeneous panel causality analysis," Energy Policy, vol. 39, pp. 6615-6621.

[18] J. Bai and C. Kao, On the estimation and inference of a panel cointegration model with cross-sectional dependence. in, B.H. Baltagi, Ed. "Panel data econometrics: theoretical contributions and empirical applications," Amsterdam: Elsevier, 2006:3-30.

[19] T.S. Breusch and A.R. Pagan, "The lagrange multiplier test and its applications to model specification in econometrics," The Review of Economic Studies, vol. 47, pp. 239-253, 1980.

[20] M.H Pesaran, General diagnostic tests for cross section dependence in panels. Cambridge: University of Cambridge; 2004, (Working Papers in Economics No. 04350435).

[21] M.H. Pesaran, A. Ullah and T. Yamagata, "A bias-adjusted LM test of error cross section independence," Econometrics Journal, vol. 11, 105-127, March 2008.

[22] J. Breitung, "A parametric approach to the estimation of cointegration vectors in panel data. Econometric Reviews, vol. 24, pp. 151-173, May 2005.

[23] M.H. Pesaran, and T. Yamagata, "Testing slope homogeneity in large panels," Journal of Econometrics, vol. 142, pp. 50-93, Jan 2008.

[24] L.V.Smith, S. Leybourne, T.H. Kim and P. Newbold, "More powerful panel data unit root tests with an application to mean reversion in real exchange rates." Journal of Applied Econometrics, vol. 19, pp. 147-170, March 2004.

[25] K.S. Im, M.H. Pesaran and Y. Shin, "Testing for unit roots in heterogeneous panels." Journal of Econometrics, vol. 115, pp. 5374, July 2003.

[26] M.V. Hood, Q. Kidd and I.L. Morris, "Two sides of the same coin? Employing Granger causality tests in a time series cross-section framework," Political Analysis, vol. 161, pp. 324-344, May 2008.

[27] S.R. Paramati, M. Ummalla, and N. Apergis,"The effect of foreign direct investment and stock market growth on clean energy use across a panel of emerging market economies." Energy Economics, vol. 56, pp. 29-41, May 2016.

[28] F. Emirmahmutoglu, and N. Kose, "Testing for Granger Causality in heterogeneous mixed panels." Economic Modeling, vol. 28, pp. 870-876, May 2011.

[29] M. Shahbaz, S.J.H. Shahzad, M.K. Mahalik and P. Sadorsky, "How strong is the causal relationship between globalization and energy consumption in developed economies? A countryspecific time-series and panel analysis," Applied Economics, vol. 50, pp. 1479-1494, Aug 2017. 